\title{
Health risk assessment of heavy metal exposure in urban soil from Seri Kembangan (Malaysia)
}

\begin{abstract}
Heavy metals in urban soils are associated with direct and indirect human health risks. This study examined bioavailability of heavy metal $(\mathrm{Pb}, \mathrm{Cd}, \mathrm{Cr}$ and $\mathrm{As})$ in urban soil of Seri Kembangan (Malaysia) and their risks to human health. Bioavailability of heavy metal concentration (arsenic, lead, cadmium and chromium) were analysed by a simplified physiologically based extraction test. Both noncarcinogenic and carcinogenic risks were assessed using health index and total lifetime cancer risk, respectively. Average concentrations of bioavailability heavy metal were found in the order of $\mathrm{Pb}(2668.8$

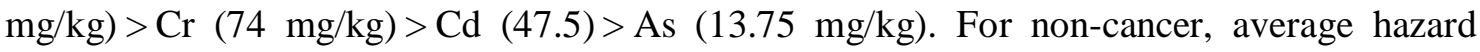
index values of heavy metal order were $\mathrm{Pb}(1.27) \mathbb{A} \mathbb{C r}(0.11) \mathbb{A} \mathbb{C} \mathrm{d}(0.05)$. For As, total cancer risk values of Seri Kembangan urban soil (7.2E-6) were lower than the tolerable lifetime cancer risk for regulatory purposes (1E-5). Ingestion pathway is the most contributed pathway for both cancer and non-cancer risks. Land use type is found to be the main contributor which influences heavy metal exposure corresponding to health risk assessment output. Industrial areas were found to have hazard index values were lesser than residential areas in Seri Kembangan urban soil. Location areas in Seri Kembangan as near major roads with large amount of traffics were found to be more higher with HI more than 1, indicating high heavy metal contamination in urban soil due to vehicular emissions. This study has showed that realistic estimation of human health risk of heavy metal contamination in urban soils needs combination of land use type with bioavailability heavy metal concentration.
\end{abstract}

Keyword: Urban soil; Heavy metal; Human health risk assessment; Exposure pathways 